temperature varying from $102^{\circ}$ to $103^{\circ}$, pulse running from 110 to 160 , respiration quick, pupils dilated, tongue dry and of a brownish colour. I next saw the mother, who also complained in a similar manner, but with not quite such severe pain; she seeming to have recovered a little. I then saw the lad, whom I found in a semi-conscious and collapsed condition, with temperature $104^{\circ}$, pulse almost imperceptible, respiration very quick, skin cold and clammy, pupils widely dilated, and very restless-in fact in a dying condition, freces and urine being passed unconsciously. Dr. Barlow kindly met me in consultation, and we agreed that it was a case of poisoning, presumably from the salmon. In spite of all our efforts, after getting more restless, the boy gradually sank and died at three o'clock next day. At the necropsy all the organs were healthy with the exception of the brain, which was very congested on the surface, and the stomach, which was found to be in a highly inflamed condition, as were also portions of the intestines, one pioce of whlch was inflamed to such an extent as to be almost in a gangrenous state. Dr. Luff, who kindly made an analysis of the above, has sent me the following report : Stomach highly inflamed, asif it had either been inflamed or attacked by some irritant substance previously to death; the $]$ intestines also were in a very inflamed condition, but no trace of any animal or mineral poison could be detected in either of the viscera. He also examined very carefully the solder round the tin and found it in a perfect condition, and also a specimen of salmon similar to that which was supposed to have caused the mischief was found to be perfectly fresh, and in good condition, and absolutely free from any poison that could be detected. I am pleased to say that all the remaining members of the family have recovered. Think we may say that all the symptoms of the above case pointed to one of irritant poisoning; and in the absence of any metallic poison being detected, the only explanation that can be offered is that it was one of those cases where death occurred from the presence of ptomaines.

I am, Sirs, yours faithfully,

Gloucester-place, Portman-square, w. C. Stormont MURRAY.

\section{"AN IMPROVED METHOD OF GRAFTING ULCERS."}

To the Editors of THE LANCET.

SIRS,-Having had an exceptionally large number of chronic ulcers of the leg, which incapacitated the patients from work, and finally brought them into the infirmary, I tried the ordinary methods of grafting, but being disgusted with the very large number of total failures I experienced, I undertook various experiments, and at last adopted the following plan, which I distinctly disclaim as my own, but which consists in adopting and combining the ideas of several people. The success I obtained with this method was so marked that I think a large number of practitioners at home and abroad (in India especially, where I found all ulcers very intractable under ordinary treatment) will welcome it. Even when the ulcer is deep, with hard thickened edges and extending all round the limb, the method applies. Chis is to cleanse the surface well for two or three days with boracic fomentations, and then (contrary to what $I$ was taught) slightly abrade the granulations, just sufficient to cause oozing, and apply the graft directly to the abraded surface, where it is held in position by a small pile made of half-inch squares of green protective, four or five squares being placed one on the top of the other. Agraft is thus applied to every square inch of surface. And now comes the most important thing of all, and which is an idea I received from a friend. This is to encircle the limb with a fold of carbolic ganze, which extends two or three inches above and below the ulcer, where it is attached to the sound skin by collodion. The ulcer is then thoroughly dredged with boracic powder through the gauze, and the whole is wrapped in a layer of wet boracic lint, which is kept thoroughly moist. As a rule, the dressing is not disturbed for three days, when the lint is removed, and the limb well irrigated with boracic lotion, the grafts remaining perfectly secure under their heaps of protective, which again is kept in position by the gauze. The limb is then redusted with boracic powder, and done up in the wet lint, which is now changed daily. At the end of ten days the gauze and protective are removed, and each graft will be found as large as a sixpence, while those near the edges will have exercised a spermatic influence, and caused a rapid ingrowing of epithelium. Since adopting the above plan I may say I have never lost a single graft, though employed on most unfavourable surfaces-a very different result to the old way of covering the grafts with a large piece of pro. tective which retained some exudations under it, and thus bathed the tender graft in a poisonous medium, with a result that 80 per cent. of them never "took."

$$
\begin{aligned}
& \text { I am, Sirs, yours truly, } \\
& \text { RAINsFond F. GILL, M.B. Lond. } \\
& \text { Adelaide-road, N.w., July, I801. }
\end{aligned}
$$

\section{ALCOHOL AND LONGEVITY.}

\section{To the Editors of THE LANCET.}

SIRS,-I have already hinted that the effects of alcohol on longevity might-and, as I think, with reason, too-be discussed on broader principles than the mere abstract figures of insurance offices, which figures I suppose nobody in his senses disputes. I notice that Dr. Ridge states in his last letter that "it is the wildest of assumptions that the members of the general section are exposed to any less favourable conditions of health than the others (i.e., temperance section), except by reason of the pernicious effects of alcohol." Personally, I am strongly disposed to think theassumption should be in favour of the opposite opinion, and upon this point, if Dr. Ridge will allow me, I join issue, because if there are such conditions as incentives to drink it would appear to me that teetotalism must secure for its converts those less exposed to such incentives, otherwise the term incentives appears to me meaningless, or, in other words, not to exist. Admitting, however, that there are incentives to drink, and that teetotalism secures those least under their influence, it does not seem unreasonable to me that at the time members of the respective sections (i.e., teetotalers and total abstainers) present themselves for examination, although they apparently in both sections have attained a state of health such as might admit them at the same premium, nevertheless are not actually upon the same footing, and for the reason that I have hinted, which is that the majority of the abstainers are untainted to the same degree by the incentives to drink as the moderate drinkers; and, although it may be, and no doubt is, impossible to demon. strate this in individual or in a very limited number of cases, and indeed not at all, without the most jealous inspection, because, as Dr. Ridge justly points out, the two sections are made up of "all ages and occupations ;" yet I submit that, after all said, there is what $I$ may be allowed to call an unconscious process of selection going on, which is an inherent part of the whole system of teetotalism, and which in the aggregate selects subjects who have as a wide rule, although with perhaps many exceptions, more favourable conditions in the background. As an example, let us suppose a given number of medical men who are exposed to the excessive strain of competition-say, a class who are engaged in the lower walks of our profession, being solicited to join the temperance. Now we know from experience the majority of these, existing as they do under somewhat unfavourable hygienic conditions, would tend to remain among the drinkers, whereas another class of practitioners more comfortably circumstanced, would tend to become abstainers ; and at the time that this state of things was going on-as it always will go on-there can be nothing inconsistent in, nor preventive from, Dr. Ridge or others pointing to their statistics and claiming, as he does, that the two sections are made up of "people of all ages and occupations," because they will always have a minority appearing to illustrate this ; and adding, " that it is a wild assumption to suppose that members of the general section are exposed to any less favourable conditions." I say, therefore, in the sum total of either section there are different conditions, and that it is an inherent and inseparable principle incorporated within the whole system of teetotalism, and further, that the difference in these conditions accounts in a greater or less degree for the difference of mortality between the two, apart from drink. And as a kind of cross test of the truth of what I have stated, let us put it problematically, and let us suppose for a moment there is no such thing as drink in existence; and let us suppose, further, humanity divided 
into two sections, one section being placed under more favourable hygienic conditions than the other; and let us suppose A, B, C, D more favourable, E, F, G, H less favourable. We know the conditions of $\mathrm{E}, \mathrm{F}, \mathrm{G}, \mathrm{H}$, compared to $A, B, C, D$, would tend to disease and shorten life, and that their mortality would be greater than A, B, C, D. This cannot be due to drink, as, according to the hypothesis, drink is not in existence. Let us now suppose drink comes into existence, and that teetotalism is set afloat, A, B, C, D would certainly, if, as I have said, there are incentives to drink, and, being comparatively free from these incentives, represent in the majority teetotallers, or the temperance section. The abstainers would then claim, as they now do, that the longevity of $A, B, C, D$, was solely due to total absti. nence; but according to the hypothesis it could not be so, because it was greater before drink came into existence. For these and other reasons I submit the statistics of insurance offices are of no value as an index to the thera. peutic action of alcohol.-I am, Sirs, yours truly,

Queen's-road, July 24 th, 1891.

Clement H. Sers.

\section{OPIUM-SMOKING IN PULMONARY TUBER- CULOSIS.}

\section{To the Editors of THE LANCET.}

SIRS,-The interesting paper on this subject by Dr. Dill may raise a question as to the morality of opiumsmoking, and may stimulate those who regard opiumsmoking as an overwhelming vice in China (to be put down at the expense of India) to vehement protests against its introduction as a therapeutic agent. The misunderstandings and contradictions on the vexed question of opium. smoking are most striking, and one can only suppose that the shocking pictures of the opium-smoker and his den are drawn from observations influenced largely by sentiment and imagination. An equally repulsive representation, on a much larger scale, can be given of alcohol and alcohol dens, with the additional accompaniments of disease, crime, brutality, and misery in our own country, but these are scarcely ever depicted in such weird colours as opium.

Some few years ago I made the experiment of smoking crude opium with tobacco, and tried its effects in a few phthisical cases where a troublesome cough was a prominent symptom. Briefly the results were as follows:-About forty grains of opium smoked in two or three pipes of tobacco of an evening produced a mild sedative effect, with sound sleep during the night. If this quantity were exceeded the hypnotic effect was increased, and a slight headache experienced on awaking, but no dryness of the tongue or constipation. Twenty grains of opium sprinkled into two pipes of tobacco, and smoked an hour or so before bedtime, relieved cough and acted as a mild hypnotic. The continuance of this system of medieation was not persisted in for the following reasons :-1. The volatile portions of the drug did not appear to be sufficiently active as aedatives given by the stomach. 2 . The curious smell of the burning opium made a disagreeable odour throughout the house like burning leaves, and excited the curiosity of everyone to know what was being smoked.

I merely give these instances for what they are worth, and in no way wish to detract from the results obtained by Dr. Dill; on the contrary, I have formed the opinion that opium, volatilised and inhaled, retains its hypnotic and sedative properties, and loses some of its disagreeble effects. It is a question for observation; but it must be remem. bered that the smoke of opium with tobacco in a pipe is not inhaled into the lungs, and therefore is absorbed only by the mucous membrane of the mouth and fances. The Chinese method of smoking, as far as I learn from friends who have seen it done, is to place crude opium in a small metal pipe holding about thirty or forty grains ; this is lighted well up by an attendant with the aid of a charcoal cinder. A fresh reed is introduced into the stem of the pipe, and the smoker inhales the fumes of the burning opium through this into his lungs, and if he be not wellseasoned he falls off to sleep after a few inhalations. There is no "whiffing" with opium fumes; the smoke is taken internally by the action of the thorax. - I am, Sirs, your obedient servant,

Davos, July 22nd, 1891.

A. TUCKER WISE.

\section{LIVERPOOL.}

(FROM OUR OWN CORRESPONDENT.)

Hospital Sunday and Saturday in Liverpool.

THE liberality of the public this year has enabled the Committee of the Hospital Sunday and Saturday Fund to distribute the handsome sum of $£ 10,800$ among the medical charities. This is $£ 200$ above the sum distributed last year, and is one of the largest amounts ever distributed since the commencement of Hospital Sunday in Liverpool in 1871. It has only been once equalled-in 1874, when the amount was the same. The following are the sums awarded to the respective medical charities :-
Royal Infirmary
.. £2484 Hahnemann Hospital _.. £216
\begin{tabular}{llll|l} 
Royal Southern Hospital & $\ldots$ & 1728 & Hospital for Women .. \\
Northern Hospital &.. &. & $\mathbf{1 5 1 2}$ & St. Pauls Eye and Ear Hos-
\end{tabular}
Dispensaries
District Nursing Society
Children's Infirmary ..
Stanley Hospital
Fye and Ear Infirmary
Ladies' Charity
Consumption Hospitai
Convalescent Institution,
Woolton
.. 216

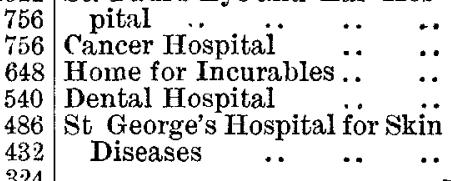
216
216
108
27

Disused City Churchyards.

The happy idea of converting old and disused city churchyards into attractive recreation grounds has been most successful. Several of the oldest, which were merely o; wilderness of neglected gravestones, have been changed into handsome flower-gardens, in which benches are placed where people may rest themselves. The experiment is to be repeated with another city churchyard in the midst of a dense population, where a pleasant recreation ground is much needed and will be much appreciated.

$$
\text { Health Resorts and Pleasure Trips. }
$$

The season at the Isle of Man, and at the favourite Welsh seaside resorts of Llandudno and Beaumaris, are very short, and are perhaps on this account all the more appreciated. The steam service from Liverpool to each of these places is now most admirably managed, and invalids may safely venture on board the splendid steamers now provided, the motion being liotle felt except in very heavy weather.

\section{Hospital Saturday in Bootle.}

The following is from a local paper:- "Charitable Enter. prise. - Bootle is to be congratulated on the success which has attended the collections this year on behalf of the Borough Hospital. This success appears to be in great part due to a little display of originality in the means adopted for gathering the donations of passers-by. Instead of birdcages being used, as in former years, and with but indifferent success, miniature representations of hospital cots have been utilised, and these cots have been 'superintended' by ladies -also a happy innovation-headed by the Mayoress of Bootle, Mrs. J. Vicars. The ladies have also greatly enhanced the success of the collection by personally soliciting. donations in the thoroughfares, armed with small and neatly decorated baskets, which, in conjunction with themselves, proved irresistible in the cause of charity. The total effect of the new departure is close upon $£ 226-$ a remarkable sum when compared with the amounts raised in previous years."

The South-west Lancashire Summer Assizes.

Mr. Justice A. L. Smith is presiding in the Crown Court at the assizes now being held here. The only charge of murder is that against John Conwav, for the murder and mutilation of a boy named Nicholas Martin, under circum. stances which caused much excitement at the time, and which has not yet wholly subsided. The judge alluded to it at length in his charge, and pointed out the more im. portant teatures, including the medical evidence. The grand jury have found a true bill against the prisoner, whose trial is fixed for Friday, the 31st inst.

Liverpool, July 28th.

\section{NORTHERN COUNTIES NOTES. \\ (From oUR OWN CORRESPONDENT.)}

\section{Presidential Addresses.}

AT the last meeting of the North of England Branch of the British Medical Association, Dr. D. Drummond, the President, merely gave a résumé of his address, which be 